УДК 81

DOI: 10.33184/YVDK-2021-04-30.42

Р.А. Газизов (проф. БаиГУ, г. Уфа)

\title{
СРЕДСТВА ВЫРАЖЕНИЯ ИМЕННЫХ ФОРМ ОБРАЩЕНИЯ В ВИРТУАЛЬНОМ ОБЩЕНИИ НЕМЦЕВ
}

В статье рассматриваются основные средства выражения именных форм обращчения, используемые немиами в СМС-коммуникации. Среди именных форм мы выделили имена существительные, представленные именами собственными и нарицательными, а также субстантивированные прилагательные и причастия. В большинстве случаев обращения распространяются оценочными прилагательными и притяжательным местоимением теin.

Ключевые слова: СМС-коммуникация, обращуение, именные формы обращения, имя существительное, субстантивированное прилагательное

The article deals with the main means of expressing nominal forms of address used by the Germans in SMS communication. Among the nominal forms, we identified nouns represented by proper and common nouns, as well as substantive adjectives and participles. In most cases, the addresses are extended by evaluative adjectives and the possessive pronoun "mein".

Key words: SMS communication, address, nominal forms of address, noun, substantive adjective.

В настоящей статье анализируются основные средства выражения именного обращения, используемые немцами при виртуальном взаимодействии друг с другом. Материалом анализа послужил корпус CMC-сообщений немецкой молодежи [SMSKorpus]. 
Как известно, обращение представляет собой речевой жанр, используемый для установления и поддержания межличностного контакта. В связи с этим оно выполняет контактоустанавливающую и контактоподдерживающую функции. Являясь значимым компонентом речевого этикета [Гольдин 1983], как и приветствие, обращение часто употребляется в начальной стадии общения. В СМСкоммуникации немецкой молодежи особенно распространены именные формы выражения обращения (ср. также местоименные, глагольные и междометные формы [Gladrow 2008: 39]), которые представлены прежде всего именами существительными. В СМСсообщениях коммуниканты используют в качестве обращения как имена собственные (a-c), так и имена нарицательные (d-f), ср.:

(a) Hy Lea.Wie geht es dir (досл.: Привет, Лея. Как дела?).

(b) Hallo Steffi! Waths up? (досл.: Привет, Штеффри! Что случилось?).

(c) Moin Tina (досл.: Доброе утро, Тина).

(d) HI SÜSSE! WIE GEHT'S? (досл.: Привет, сладкая! Как дела?).

(е) Guten Morgen Sonnenschein (досл.: Доброе ympo, солнечный светик).

(f) Gute Nacht, mein Held! Du bist ganz wunderbar (досл.: Спокойной ночи, мой герой! Ты очарователен!).

Использование имен существительных в уменьшительноласкательной форме, напр., посредством суффиксов -chen и -lein обусловлено эмоциональными факторами речевого поведения, которые позволяют передавать свое положительное отношение к партнеру по коммуникации [Gladrow 2008: 42], напр., Ninchen от Nina (a), Tinchen от Tina (b), Katilein от Kati (c):

(a) HI NINCHEN, COOL, DASS DU JETZT AUCH FERIEN HAST! (досл.: Привет, Нинхен, клево, что у тебя сейчас тоже каникульь!).

(b) HI TINCHEN, WIE GEHT ES DIR? (досл.: Привет, Тинхен, как дела?).

(c) Hi, Katilein, wir sind gut angekommen, ihr auch? (досл.: Привет, Катиляйн, мы хорошо добрались, вы тоже?).

Как и имена собственные, некоторые имена нарицательные также представлены в уменьшительноласкательной форме. Такие формы обращения выражают 
доброжелательное, теплое отношение к адресату и свидетельствуют о непринужденной обстановке виртуального взаимодействия, ср. (a) - (d):

(a) Schlaf gut, mein Mäuschen... (досл.: Спокойной ночи, мой мымонок...).

(b) Hi schneckchen! Kommt ihr denn jetzt heute abend vorbei? (досл.: Привет, улиточки! Вы загляните сегодня вечером к нам?).

(c) Hallo schnucki (досл.: Привет, ягненочек).

(d) hy mein Schnuckiputzi (досл.: Привет, мой ягненочек).

Словарь Duden [Duden 2006: 1485-1486] отмечает, что лексемы Schnucki и Schnuckiputz (в вышеприведенных примерах (c) и (d) производны от Schnuckelchen и употребляются в качестве ласкательного обращения к девушке.

Некоторые имена нарицательные, такие как Mann (мужчина, человек), Mensch (человек) могут выступать как в форме именного обращения в значении «чувак» (a), (b), так и в междометной форме, в которой они выражают удивление (c), (d) или сожаление (e) [Duden 2006: 1110, 1134]:

(a) Hey Mann, wo bleibst du? (досл.: Привет, чувак, где mbl сейчас?).

(b) Ey man, wo bleibst du? (досл.: Эй, чувак, где mbl cейчас?).

(c) MANMANMAN. SIEHT BESTIMMT NICHT SO SCHLIMM AUS (досл.: O, не так плохо выглядит).

(d) Hi nele!!man,man...du stehst ja auch immer frueh auf, was! (досл.: Привет, Неле! О-о-о ... ть так рано всегда встаешь!).

(е) Hi A, MENSCH TUT MIR LEID (досл.: Привет, A., эx, очень жаль).

Многие имена существительные распространяются некоторыми оценочными прилагательными, напр., lieb (дорогой) (a), gro $\beta$ (большой) (b), schön (красивый) (c), klein (маленький) (d) и притяжательным местоимением mein (мой) (е), а также могут употребляться в сочетании с прилагательными и местоимением mein (b). Тем самым такие обращения получают экспрессивную окраску и помогают адресанту в большей степени выразить свою доброту, любовь, заботу по отношению к близкому ему человеку, ср.: 
(a) GUTEN MORGEN LIEBE ANGELA! (досл.: Доброе утро, дорогая Ангела!).

(b) guten morgen mein großer schatz. (досл.: Доброе утро, мое большое сокровище).

(c) Guten morgen Schöne Frau, Gut geschlafen? (досл.: Доброе утро, прекрасная дама, хорошо спали?).

(d) Hallo Kleine maus, hoffe du hast meine sms gestern bekommen! (досл.: Привет, маленький мышионок, надеюсь, ты получила вчера мое сообщение).

(e) Morgen mein Held! Würde gerne in ... aufwachen. (досл.: Доброе утро, мой герой! Я бы проснулась в ...).

Необходимо отметить, что среди именных форм обращения можно выделить также имена прилагательные и причастия, которые субстантивируются и используются как субстантивированные прилагательные и причастия, напр., Süßе от süß (a), Große от groß (b), Liebes от lieb (c), Kleines от klein (d), Verschollene от verschollen (verschallen - без вести пропасть) (e): дела?).

(a) Na Süße, wie geht's Dir? (досл.: Нy, сладкая, как у тебя

(b) Hi Große. Sind noch bei Mama. (досл.: Привет, больиие. Bbl еме у мамы).

(c) Hi Liebes, sind gut auf Sylt angekommen, ... LG PA U. Ma (досл.: Привет, любимые, мы хорошо добрались до Зильта, ... с наилучшими пожеланиями папа и мама).

(d) Na kleines was machst du? (досл.: Hy, мальиш, чем ты занимаешься?).

(е) Hallo Verschollene. Wie gehts? (досл.: Привет, без вести пропавшие. Как дела?).

Как и имена существительные, субстантивированные прилагательные могут распространяться, напр., посредством притяжательного местоимения mein, которое повышает, на наш взгляд, эмпатийный потенциал всего обращения, ср., (a) - (d):

(a) Hey meine Kleine! Alles Gute für Deine Klausur (досл.: Привет, моя мальика! Всего хорошего тебе при написании экзаменационной работь).

(b) HALLO MEINE SüßE, WIE GEHT ES DIR (досл.: Привет, моя сладкая, как у тебя дела?). 
(c) Ciao, meine Schöne! Ruf mich doch einfach morgen an (досл.: Пока, моя красавища! Позвони мне завтра).

(d) Na meine Liebste, ich habe heute in Sport am Barren geglänzt! (досл.: Нy, моя любовь, я сегодня блистал на брусьях).

Причем некоторые прилагательные используются в превосходной степени, что усиливает степень выражения доброжелательного отношения к своему партнеру по переписке (см. пример (d), ср. также: Hi mein größter Schatz! (досл.: Привет, мой самое большое сокровище!). В этом примере используется лексема Schatz, которая имеет в своем значении положительную коннотацию, поэтому к ней прибегают довольно часто в качестве ласкательного обращения для выражения своих теплых чувств к адресату. Данная лексема может употребляться самостоятельно (a), (b), а также в сочетании с некоторыми прилагательными, напр., lieb (c), allerlieb (d), gro $\beta$ (см. вышеприведенные примеры):

(a) Hi schatz. Bist Du ... gekommen? (досл.: Привет, сокровище. Ты приехала?).

(b) Hi Schatzi! Sag denen mal bitte, dass das Büro wieder komplett einsatzbereit ist (досл.: Привет, сокровище! Передай, пожалуйста, им, что офис полностью готов).

(c) Ich bin gut angekommen, mein lieber Schatz (досл.: $Я$ хорошо доехал, мое дорогое сокровище).

(d) Schlaf gut, mein allerliebster Schatz! (досл.: Спокойной ночи, мое самое дорогое сокровище).

Вышеописанная лексема относится к так называемым метафоризованным номинациям, обозначающим названия предметов, явлений действительности, животных, ср. также лексемы Maus/Mäuschen/Mausi (мышь/мышонок), Schneckchen (улиточка), Schnucki (ягненочек).

Помимо лексемы Schatz к ласкательным обращениям относится также субстантивированное прилагательное Süße (a), которое может графически использоваться в формах Süssa (b) и Süssä (c), а также в сочетании с притяжательным местоимением mein (d), cp.:

(a) Hallo Süsse, kannst Du am Sa. um 12.00 Uhr arbeiten kommen? (досл.: Привет, сладкая, ть сможешь прийти в субботу в 12.00 на работу?). 
(b) Hi Süssa ich Liebe dich und vermisse dich (досл.: Привет, Сладкая, я люблю тебя и скучаю по тебе).

(c) Ich liebe dich Süssä (досл.: Я люблю тебя, сладкая).

(d) Hallo meine süsse. Freu mich schon aufs Wochenende (досл.: Привет, моя сладкая. Уже радуюсь предстоящим вьиходнылм).

В СМС-коммуникации в качестве именных форм обращения могут использоваться антропонимические сокращения, т.е. сокращенные варианты имен собственных. Данный способ применяется в целях языковой экономии, к которой коммуниканты часто прибегают в письменной речи. Усечение личных имен представляет собой один из самых продуктивных способов языковой экономии на лексическом уровне языка, ср. (a), (b):

(a) Hallo S.! Wir treffen uns um halb neun vor Cafe Sieben! (досл.: Привет, С.! Встретимся в половине девятого возле кафе Зибен!).

(b) HI X! WO BIST DU GERADE? (досл.: Привет, Kc.! Tbl где сейчас находишься?).

Использование терминов родства при обращении к собеседнику определяется социальными факторами речевого поведения. Так, по отношению к близким родственникам возможно, к примеру, употребление лексемы Cousine (двоюродная сестра): hi cousine! schicke die handyNr v. Matzi! (досл.: Привет, кузина! Пришли номер сотового телефона Матцฺи!).

Обращения как в устной, так и письменной коммуникации могут заменять речевые акты приветствия (a), а также употребляться в сочетании с формулами поздравления (b) и пожелания (c), ср.:

(a) ELSI - MEIN SCHATZI! HOW ARE YOU! (досл.: Эльзи - мое сокровище! Как у тебя дела?).

(b) Liebe Kirsten! Happy birthday von Isabel, Lea und Ralf (досл.: Дорогая Кирстен! C днем рождения поздравляют тебя Изабель, Леа и Ральф).

(c) Schlaf gut, Du Süßer! (досл.: Спокойной ночи, сладкий!).

Таким образом, именные формы обращения в СМСкоммуникации немецкой молодежи находят широкое 
применение. Среди основных средств можно выделить имена собственные и нарицательные, субстантивированные прилагательные и причастия. Если имена существительные распространяются, как правило, оценочными прилагательными, то субстантивированные прилагательные чаще употребляются в сочетании с местоимением mein, что повышает эмпатийный потеницал обращения и способствует реализации некоторых стратегий вежливости для выражения симпатии, любви, доброжелательного отношения к собеседнику.

\section{ЛИТЕРАТУРА:}

1. Гольдин В. Е. Речь и этикет / В. Е. Гольдин.- М.: Просвещение, 1983. - 109 с.

2. Gladrow, W. Система обращения в русском и немецком языках // Slavica Helsingiensia 35. C любовью к слову. Festschrift in Honour of Professor Arto Mustajoki on the Occasion of his $60^{\text {th }}$ Birthday. Ed. by Jouko Lindstedt et al. Helsinki, 2008. - S. 38 48.

3. Duden. Deutsches Universalwörterbuch. 6., überarbeitete und erweiterte Auflage. Hrsg. von der Dudenredaktion. Mannheim, Leipzig, Wien, Zürich: Dudenverlag, 2006. $2016 \mathrm{~S}$.

4. SMS-Korpus [Электронный pecypc]. URL: http://www.mediensprache.net/archiv/corpora/sms_os _h.pdf (дата обращения: 10.03.2021).

(C) Газизов P.A., 2021 г. 